\title{
OFÍCIO DE POLÍCIA, VIOLÊNCIA POLICIAL E LUTA POR CIDADANIA EM MATO GROSSO
}

\author{
Naldson Ramos da Costa \\ Resumo: O ofício de polícia em Mato Grosso tem sido marcado pela violência policial nas práticas de contro- \\ le social. Isso vem fomentando a luta por cidadania e o respeito ao Estado Democrático de Direito. O artigo \\ trabalha ainda com idéia de que a universidade tem um papel importante na formação e construção de uma \\ polícia cidadã. \\ Palavras-chave: violência policial; controle social; cidadania. \\ Abstract: The police force in Mato Grosso State is considered violent in the manner in which it executes \\ social control. This has fueled the struggle for civil rights and for a respect for democratic rule of law. The \\ article further explores the idea that the university has an important role to play in the formation and construction \\ of the police-citizen. \\ Key words: police violence; social control; citizen rights.
}

$\mathrm{A}$ problemática da violência e da criminalidade na sociedade mato-grossense nestas duas últimas décadas tomou proporções que vêm preocupando as autoridades e gerando a insegurança entre a população. Assim como no Brasil, a violência encontra-se difu$s a$ por todas as redes de sociabilidade e poder. Nas redes de sociabilidade mato-grossense é comum o emprego da violência como forma de resolver os conflitos entre as relações interpessoais e nas que contrapõem os interesses das elites e das não-elites.

Ela está presente inclusive nas instituições encarregadas de combater a violência e de promover a justiça. Os órgãos de segurança, representados pelas polícias Civil e Militar, aparecem constantemente envolvidos em violência policial cometida principalmente contra as populações segregadas e suspeitas de algum crime.

$\mathrm{O}$ entendimento da origem da violência policial e da criminalidade em Mato Grosso passa pela tese desenvolvida por O'Donnell (1988), segundo a qual essa violência tem suas raízes num passado marcado pelo "autoritarismo socialmente implantado". Para Pinheiro (1997:47), as práticas autoritárias seriam ainda resultado direto da continuidade e de uma longa tradição de autoritarismo das elites contra as não-elites que, por sua vez, são reproduzidas entre os mais pobres. Essas práticas autoritárias e violentas são empregadas também pelos órgãos encarregados de fazer a segurança e promover a justiça em nosso país. Pinheiro reforça sua tese dizendo que essa violência é "endêmica" e faz parte, desde o Brasil tradicional, da estrutura social e política brasileira. Ela continua presente nessas estruturas sociais e de poder mesmo depois do período republicano e pós-redemocratização do país em 1988. O maior dilema das autoridades brasileiras tem sido a dificuldade de mantê-la sob o controle dos governos, num país tão marcado por desigualdades e onde as leis são constantemente desrespeitadas pelas elites e até mesmo pelas autoridades. Ainda segundo Pinheiro (1997), há no Brasil um enorme gap entre o que está escrito na lei e a realidade brutal da aplicação da mesma.

Na visão de Skolnick (1966), no que se refere à violência policial, no entanto, a experiência policial e as suas práticas girariam em torno da combinação de perigo e autoridade. É o perigo que vai pôr em risco o emprego da autoridade. Desta forma a adesão do policial às normas legais variaria de acordo com o perigo a que é exposto. Assim, o policial pode empregar o uso da força ilegal de 
acordo com o perigo a que ele se sente submetido, ou quando a sua autoridade é questionada ou desrespeitada. Contra os cidadãos oriundos das camadas populares, de onde vem a maioria dos delinqüentes, o policial acaba agindo como mais rigor ou com excesso de poder e arbitrariedade, porque os julgam, com base em critérios subjetivos e baseados na condição de classe ou de cor, como criminosos em potencial que colocariam em risco não só a ordem social, como a sua própria vida. Já no relacionamento com as elites, ele tende a ser mais civilizado, porque teoricamente essas pessoas não oferecem nenhum risco à sua segurança, exceto quando ele não reconhece o prestígio e o poder dessa pessoa como membro de um grupo ou de uma classe social considerada privilegiada.

Por essas razões é que Caldeira (2000) afirma que existe um hiato entre a legalidade formal e a cidadania. Essa cisão entre democracia formal e práticas de controle social deu origem ao que ela denomina de "democracia disjuntiva". Essa disjunção reflete-se no descompasso entre cidadania política e cidadania civil. A tradição de uma cultura autoritária, violenta, enraizada como costumeira, somada ao gap e ao descompasso entre a lei e a cidadania civil, faz com que a democracia não se efetive para a maioria da população, visto que ela não tem razão de não terem acesso aos instrumentos legais de defesa dos seus direitos, configurando-se naquilo que Tavares dos Santos (1993) denominou de "cidadania dilacerada".

Em Mato Grosso, o ofício de Polícia está fortemente associado a esse passado autoritário, marcado pelo uso ilegítimo da força para conter o aumento da criminalidade. As políticas de segurança pública no Estado das duas últimas décadas vêm encontrando dificuldades em arbitrar os conflitos e combater a criminalidade, respeitando o monopólio legítimo da violência e os direitos dos cidadãos. As formas e as práticas de controle social têm resultado em violência policial e no desrespeito aos direitos humanos. Essas são as premissas das quais partimos para situar o ofício de polícia e a violência em Mato Grosso.

A prática de controle social baseada numa cultura autoritária e no uso ilegítimo da força (excesso de poder) vem comprometendo o Estado Democrático e atentando contra os direitos humanos. Nesse contexto, trabalho com a hipótese de que as universidades e as academias têm um papel de destaque na formação de uma polícia que atue de acordo com as normas e preceitos democráticos.

A violência e a criminalidade foram aceleradas em Mato Grosso, em particular na capital Cuiabá, devido ao processo de ocupação e expansão das suas fronteiras agríco- las mediante uma política de colonização oficial e particular (Tavares dos Santos, 1997a), que deu origem a uma urbanização acelerada e desordenada, ao lado do crescimento dos problemas sociais e da criminalidade, tanto no campo como nas cidades.

Mas é partir da década de 90 que emergem os conflitos que resultarão no aumento da exclusão social, da violência e da criminalidade. Os conflitos, nesse novo espaço de sociabilidade, ao invés de caminharem em direção ao desenvolvimento integrado e ao "processo civilizatório" (Elias, 1999), como era de se esperar, tiveram uma direção bem diversa. A violência logo tornou-se realidade nas periferias das cidades e entre as redes de poder.

Em virtude dos conflitos decorrentes das redes de sociabilidade e poder e do aumento da criminalidade, são muito comuns em Mato Grosso, nos dias atuais, as práticas de controle social ou de solução dos conflitos com base no uso ilegítimo da força policial ou de crimes de pistolagem e violência privada. Essas práticas encontramse fora do controle do "monopólio legítimo da violência" (Weber, 1991), fazendo de Cuiabá uma das cidades mais violentas. ${ }^{1} \mathrm{O}$ aumento da violência policial, ${ }^{2}$ por sua vez, vem atentando contra os direitos humanos e o Estado de Direito.

Em síntese, esse é o quadro da criminalidade e da violência que vem se agravando no Estado de Mato Grosso (Tabela 1), nos últimos anos, a ponto de fazer de Cuiabá a $3^{a}$ capital mais violenta do país, sendo ainda a campeã no aumento em número de homicídios contra os jovens, conforme pesquisa da Unesco sobre violência nas capitais brasileiras (Unesco, 2000) divulgada em 2000. ${ }^{3}$

TABELA 1

Ocorrências Policiais

Mato Grosso - 1997-2000

\begin{tabular}{lrrrr}
\hline Violência contra a Pessoa & 1997 & 1998 & $1999(1)$ & $2000(2)$ \\
\hline Agressões & 2.269 & 2.378 & 1.603 & - \\
Tentativas de Homicídios & 1.277 & 1.400 & 306 & - \\
Homicídios & 369 & 473 & 319 & 180 \\
\hline
\end{tabular}

Fonte: Secretaria de Segurança Pública - Polícia Militar; IML-MT.

(1) Dados do 10 semestre.

(2) Dados do 10 semestre. Homicídios na imprensa de Mato Grosso.

A violência policial encontra-se presente em todas as corporações policiais brasileiras. As possibilidades de controle e sua diminuição estão relacionadas à realização de reforço dos sistemas de accountability ${ }^{4}$ (Chavigny,1995). Enquanto os policiais não forem responsabilizados e punidos por atitudes ilegais e extralegais, a violência e os abusos 
tendem a permanecer como uma prática usual e comum do ofício de polícia. A impunidade tem sido considerada a principal motivadora do emprego indiscriminado da força, como se o uso ilegítimo da força fosse considerado inerente à atividade policial.

A falta de controle da violência, difusa e policial, vem revelando a fragilidade das políticas de formação e controle do ofício de polícia. Por isso, as fronteiras entre o legal e o ilegal são instáveis. Como os abusos policiais são cometidos, na maioria das vezes, impunemente, não só a polícia é temida, mas também os sistemas de justiça criminais são deslegitimados e não percebidos como recurso confiável na busca dos meios legais de solução dos conflitos (Caldeira, 2000:155).

Os desvios no ofício de polícia, em Mato Grosso, não diferem muito dos padrões praticados na maioria das federações brasileiras. As práticas e a cultura do ofício, segundo Bretas (1997:82) estão muito associadas ao autoritarismo, ao conservadorismo, ao cinismo, ao pessimismo, ao machismo, que resultam em truculência e na idéia de que existe um inimigo da sociedade. Isso contrapõe-se aos direitos humanos, aos códigos de conduta ética e profissional ensinados nas Academias e Centros de Formação Profissional.

O crescimento da violência policial vem sendo associado ainda à ineficiência do aparelho policial, à ineficiência do Judiciário e à impunidade dentro das corporações de ofício. Essa impunidade e ineficiência do sistema criminal são motivadoras e incentivadoras das ações truculentas e ilegais dos grupos privados e dos órgãos de segurança. Alguns policiais (civis e militares), devido ao baixo controle, consideram-se acima da lei e acreditam que a solução para a violência e a criminalidade está na ação truculenta das forças policiais. Esses policiais contam ainda com o apoio de parte da população e com a possibilidade de não serem denunciados, julgados e punidos exemplarmente por suas atitudes violentas e arbitrárias. Alguns depoimentos na imprensa local deixam clara a visão da sociedade e policiais. ${ }^{5}$

No Mato Grosso, essas denúncias pela imprensa de violência policial ou de "justiceiros" revelam como a violência encontra-se privatizada e presente nas práticas e na cultura do ofício de polícia, contando com apoio inclusive de parte da população e de alguns programas televisivos que têm como matéria-prima a notícia policial. Essas notícias de jornais ilustram como Cuiabá continua sendo uma cidade violenta, apesar dos esforços das autoridades da área de segurança. Os dados de 1999, relacionados ao número de homicídios, por exemplo, indicam que a rela- ção de mortos por habitantes atingiu a faixa de 51 para $100 \mathrm{mil} /$ habitantes (Viana, 2000:26).

O modelo de polícia e de controle social em Mato Grosso encontra-se ainda associado ao militarismo e ao autoritarismo, tendo como missão a idéia de que existe "um inimigo" da sociedade e do Estado. Para ser eficientes na repressão, alguns policiais acham que têm de combater o criminoso a todo custo e com todos os meios. Com isso, acabam identificando o delito (crime) ao criminoso, o que justifica o uso da força física. Esse "inimigo" é visto como uma ameaça à segurança do Estado e à ordem social.

Chavigny (2000:65) afirma que o papel da polícia na América Latina foi definido erroneamente, pois "muitos políticos de forma impensada aceitam um modelo semimilitar no qual o papel da polícia é 'combater' o inimigo 'crime', incorporado à pessoa do criminoso".

Esta definição do papel da polícia é que tem gerado uma interpretação equivocada da missão do policial em garantir segurança para si e para sociedade. É com base nesse modelo de polícia que vários governos vêm planejando suas políticas de segurança e ditando as práticas de controle social baseadas no aumento da repressão ao crime de forma violenta.

Esse modelo é responsável, em grande medida, pelo desvio de conduta, pela violência policial e pela não efetivação do Estado de Direito no Brasil. O modelo semimilitar veicula que, para ser "eficiente" em sua missão de controlar a população e de "combater o inimigo", é preciso fazer uso constante da força ilegítima para imobilizar os oponentes da lei. Outra prática que tem extrapolado os limites legais do uso da força é a representada pela utilização indiscriminada da arma de fogo, a exemplo do que ocorre no Rio de Janeiro, onde é grande o número de mortos e feridos em confronto com a polícia (Cano, 1997).

Em algumas Academias de Polícia, ainda permanece nos currículos a idéia do "policial guerreiro" e da existência de um "inimigo da sociedade" que precisa ser derrotado a todo custo, a fim de resguardar os nossos valores e preservar a vida e a propriedade. Essa cultura acaba por reforçar a violência no ofício de polícia, conforme demonstra o trabalho desenvolvido por Albuquerque (1999). Nesse trabalho, o autor demonstra a relação estreita entre o currículo existente na Academia de Polícia associada com essa imagem guerreira, militar, em que se celebra um tempo no qual a polícia tinha prestígio, o monopólio da força bruta, e era por isto legitimada. Em Mato Grosso, até o final da década de 90, era muito comum os instrutores da Academia e do Centro de Formação Profissional - Cefap empregarem técnicas e táticas militares que valorizavam 
a idéia de policial "guerreiro", ou humilhações do tipo: "beber sangue de galinha", ser afogado, arrastar-se na lama, levar "tapa na cara".

Essas formas variadas assumidas pela violência difusa e a violência decorrente do ofício de polícia é que vem comprometendo o Estado Democrático de Direito e desrespeitando os direitos humanos em Mato Grosso.

\section{LUTAS SOCIAIS CONTRA A VIOLÊNCIA POLICIAL}

Para contrapor-se a essa onda de violência presente nas redes de sociabilidade e poder, representada pelas práticas de torturas, pelas execuções sumárias, pela violência nos presídios, pela violação dos direitos humanos em Mato Grosso, várias instituições vêm trabalhando no sentido de denunciar essas práticas e exigindo das autoridades do Executivo e do Judiciário a punição dos responsáveis. Entre essas instituições, destacam-se os Centros de Defesa dos Direitos Humanos ligados à Igreja: Centro de Defesa dos Direitos Humanos Henrique Trindade (Cuiabá), Centro de Defesa dos Direitos Humanos Simão Bororo (Rondonópolis), Centro de Defesa dos Direitos Humanos de Cáceres (Cáceres); a Ordem dos Advogados/OAB-MT; a Associação dos Familiares e Vítimas de Violência AFVV; a Associação de Proteção e Assistência aos Condenados - APAC; a Comissão de Direitos Humanos da Assembléia Legislativa (1999) e da Câmara dos Vereadores de Cuiabá (1999), entre outras manifestações públicas envolvendo partidos políticos de esquerda, CUT, sindicatos e universidade.

Foram essas instituições da sociedade civil que deram subsídios para a elaboração do relatório em que o representante da Comissão de Direitos Humanos da ONU, Nigel Rodley, incluiu Mato Grosso como um Estado que viola os direitos humanos. Este relatório divulgado em Genebra (Suíça), no dia 11 de abril de 2001, reforça o que já era do conhecimento de toda a sociedade e das autoridades governamentais. Em determinada parte afirma-se textualmente que "a tortura está entronizada não apenas como técnica de investigação da polícia, mas em métodos de controle disciplinar nas instituições penais, servindo também para fortalecer esquemas de extorsão em seus bastidores".

Esse relatório da ONU de certa forma foi confirmado pelas autoridades locais e pelos representantes dos direitos humanos. Conforme declarações dadas ao Diário de Cuiabá, de 22/04/2001, reconhecendo a existência e a prática de tortura no ofício de polícia, bem como a necessidade de controlá-la.
O aumento da criminalidade e da violência policial em Mato Grosso, na década de 90 e início de 2000, vem obrigando governo e sociedade civil a se organizarem para fazer frente ao desrespeito aos direitos humanos e para resguardar o Estado Democrático de Direito, fortalecendo desta forma a cidadania civil. As denúncias de vítimas da violência policial são constantes e nem sempre esclarecidas e punidas exemplarmente. Policiais e autoridades admitem essa prática com a maior naturalidade, apesar de reconhecerem que ela compromete a imagem das corporações e atentam contra os direitos humanos. Notícias como estas são bastante comuns nos meios de imprensa locais:

- Ussiel Tavares, presidente da OAB em MT. Para ele "a assistência jurídica gratuita, principalmente no estágio de detenção, é ilusão para $85 \%$ dos presos. Criticou o fato de o governo do Estado ter contratado apenas 43 defensores públicos para atender a população carente do Estado. Sobre o relatório, disse que OAB pretende retomar imediatamente as discussões a respeito da garantia aos direitos humanos e, especialmente, das variadas formas de violência policial".

- Corregedorias de Polícias: Civil e Militar. "Todas as denúncias são apuradas e, caso comprovadas, resultam em punição dos responsáveis, sem exceção", sustenta Silas Tadeu Caldeira, corregedor da Polícia Civil. Segundo ele, desde 1995, quando foi criada a corregedoria, 70 agentes foram demitidos, por crimes que vão da tortura ao abuso de poder. Outros 200 foram suspensos, advertidos ou repreendidos. Ao todo, mais de mil denúncias foram registradas contra policiais neste período.

- Na Polícia Militar, o corregedor Cel. Jorge Roberto Ferreira da Cruz incentiva o cidadão que se sentir prejudicado pela ação da policial a procurá-lo diretamente. Desde a sua criação, em 1994, a Corregedoria Militar abriu 671 IPMs, 971 sindicâncias e 243 PADMs para apurar a conduta de integrantes da corporação. Ao todo, 127 foram excluídos, sendo quatro oficiais.

- Desembargadora Shelma Lombardi de Kato. "As normas e tratados internacionais sobre direitos humanos assinados pelo Brasil têm a força de matéria constitucional. Mas não é isso que acontece na prática. Isso porque a falta de capacitação na matéria leva muitos juízes e promotores a abrandar penas de torturadores. Em relação à tortura, o Poder Legislativo é incoerente e o Executivo é omisso. O Judiciário peca pela falta de capacitação de seus membros em relação aos Direitos Humanos".

- Delegado Dirceu Vicente Lino, presidente do Sindicato dos Delegados de Polícia (Sindepol). "A tortura, apesar 
de ainda ser utilizada como instrumento de investigação, é uma prática em desuso. As resistências a mudanças eu atribuo ao despreparo e à falta de condições de trabalho. Aquele policial do pau-de-arara, que acha que confessar é obrigatório, está sendo banido do nosso contexto. A polícia vem mudando mas, infelizmente, ainda há colegas que defendem este tipo de comportamento".

- Teobaldo Witter, pastor, coordenador do Centro de Defesa de Direitos Humanos Henrique Trindade de Cuiabá. "A PM foi treinada para fazer guerra contra o povo. E, até hoje, não perdeu essa mania de vê-lo como inimigo. Problemas sociais não se trata com polícia, mas com política. A missão da polícia tem a ver com o combate e a prevenção do crime. A atuação da polícia em Mato Grosso não foge à descrição contida no relatório da ONU. A tortura é uma realidade nos nossos presídios e delegacias, alimentada pela certeza da impunidade. Os torturadores têm certeza que nada irá acontecer".

As denúncias reconhecendo as práticas de tortura que partem da sociedade civil e de entidades de direitos humanos por si só não reduzem os índices de violência, como é demonstrado pelos dados do Mapa da Violência de Cuiabá, ${ }^{6}$ apresentados pelo deputado do PT, Gilney Viana (2000). No entanto, essas entidades têm sido importantes aliadas das pessoas que tiveram seus direitos desrespeitados. Apesar dessas lutas, Cuiabá é uma cidade cada vez mais violenta por continuar apresentando índices crescentes de criminalidade e de desrespeito ao Estado Democrático. ${ }^{7}$

Todavia, adverte Mesquita Neto (1999:147) "em regimes políticos democráticos, como acontece no Brasil, é inútil, além de desumano em relação aos policiais, criticar e procurar controlar a violência policial recorrendo simplesmente a mecanismos de controle formal, sejam eles internos ou internos à organização policial, e mecanismos de controle informal externo, sem oferecer aos policiais a capacitação profissional necessária para o desempenho de suas funções com um uso mínimo da força física".

Esta constatação representa um avanço na busca de uma melhor qualificação para os policiais e em direção à construção de uma segurança e uma polícia cidadã. As universidades e os movimentos sociais, principalmente o movimento de direitos humanos, estão percebendo que a questão da segurança e da cidadania é uma construção social. Não basta, portanto, ficarmos cobrando ou só denunciando os abusos, os excessos e a violência cometida por agentes estatais. É necessária uma aproximação desses setores para conhecer melhor a realidade e as condições de trabalho destes servidores públicos e, juntos, construirmos novos modelos e novas práticas voltadas para aumentar a segu- rança dos cidadãos e fortalecermos os processos de decisão democráticos. Faz-se necessário sair do estranhamento para o reconhecimento. O estranhamento é marcado pelo preconceito, juízos de valor negativos e pela incompreensão. Já o reconhecimento pressupõe a idéia de que ninguém é dono da verdade, que não existe verdade absoluta, que é nas diferenças que se constrói a unidade, a busca de alternativas consensuais, e que se valoriza e se reconhece a importância do trabalho do outro. As questões sociais, como a violação dos direitos humanos, representada pela tortura, pela violência policial, pela violência contra a criança e o adolescente, contra a mulher, são problemas que requerem uma reflexão pluridisciplinar, multifocal e interinstitucional. É desse diálogo, aberto, franco, democrático, que surgem consensos e propostas visando uma melhor qualificação dos profissionais da segurança do cidadão e que podem aproximar as instituições policiais e as universidades.

\section{PAPEL DA UNIVERSIDADE NA FORMAÇÃO E CONSTRUÇÃO DE UMA POLÍCIA CIDADÃ}

Preocupada em proporcionar uma melhor formação aos seus policiais, a Polícia Militar de Mato Grosso firmou um convênio com a Universidade Federal de Mato Grosso, em $1993,{ }^{8}$ mediante o qual esta se responsabilizava pela realização do vestibular que dá acesso à carreira de oficial da polícia do Estado - iniciativa inédita no país. A universidade encarregava-se também de oferecer aos futuros oficiais disciplinas nas áreas de humanidades, tais como: sociologia, filosofia, direito, psicologia, entre outras. Em 2000, o currículo da Academia de Polícia da Costa Verde, do município de Várzea Grande, MT, passou por reformulações, de modo a adequar a formação destes profissionais à nova proposta curricular elaborada pela Fundação João Pinheiro e pelo Ministério da Justiça.

Esse novo currículo incorporou novas disciplinas, tendo em vista ampliar o debate acerca da questão da segurança pública e do respeito ao Estado de Direito. Entre as disciplinas integradas ao novo Projeto Político Pedagógico da Academia da Costa Verde estavam: Ofício de Polícia e Políticas de Segurança Pública, Sociologia da Violência e da Criminalidade, Abordagens Sociopsicológica da Violência, Filosofia e Ética, Direitos Humanos, Filosofia de Polícia Comunitária - todas elas visando, na área de direito, o respeito ao Estado de Direito e a promoção da cidadania.

No segundo semestre de 2002, a Universidade Federal e a Polícia Militar assinaram protocolo de intenções para 
a instalação de um posto avançado de policiamento comunitário no campus universitário, para garantir a segurança de seus freqüentadores. A universidade está em fase final de construção do prédio que irá abrigar o posto e a polícia já vem fazendo o policiamento de bicicletas ou a cavalo. Acredita-se que a partir desse policiamento e dessa experiência se possa estabelecer um "projeto-piloto" de policiamento comunitário que poderia ser levado para outros bairros e regiões.

No segundo semestre de 2002, iniciou-se na universidade um debate envolvendo professores interessados em formar um Núcleo de Estudos da Violência e da Cidadania. Os debates concluíram pela importância de aglutinar professores e outras instituições interessadas no estudo da violência e da criminalidade, bem como de encontrar respostas para superar a cultura da violência difusa na sociedade e nas polícias. Manifestou-se também a intenção de promover pesquisas com os mais diferentes enfoques e nas mais diferentes áreas a fim de subsidiar políticas de segurança pública nas esferas e governo municipal, estadual e federal.

A proposta aprovada no âmbito da Universidade Federal do Mato Grosso/Instituto de Ciências Humanas e Sociais - UFMT/ICHS visa agregar professores de diferentes áreas, em uma perspectiva pluridisciplinar, representantes de ONGs, líderes comunitários, militantes de direitos humanos, membros do Ministério Público, OAB, Igrejas, membros das Polícias Militar e Civil e outras instituições ou pessoas preocupadas com a questão da violência na sociedade mato-grossense. Por essa razão, optou-se pela criação de um Núcleo Interistitucional - NIEVCI com participação de professores pesquisadores e demais pessoas ligadas a instituições não-governamentais e governamentais nas três esferas da administração pública.

Para contrapor-se a essa onda de violência policial e ao modelo de polícia baseado na ideologia militarista é que se faz importante a parceria entre as universidades, academias de polícia e governos (municipal, estadual e federal), já que o controle institucional dessa violência, feita pelas corregedorias, e a luta pelos direitos humanos não têm sido capazes de colocar um freio nessa escalada da violência policial. A impunidade tem sido a responsável pela continuidade dessas práticas no interior das corporações, de tal forma que às vezes pensamos que a violência policial é inerente à atividade de segurança pública. Entretanto, mais do que controlar e punir é preciso profissionalizar a polícia, assegurar melhores condições de trabalho, pois esse é um passo importante e necessário para o controle da violência policial.
De fato, a melhoria dos serviços prestados pelos profissionais da segurança do cidadão passa necessariamente pela questão da formação desses profissionais. Porém, não deve entender essa formação como sendo capaz de corrigir e impedir a violência policial, pois sabemos que outros fatores também influenciam os excessos que são cometidos por esses policiais que acabam extrapolando o monopólio da violência legítima e o Estado Democrático de Direito. É preciso pensar a questão da formação como um processo educativo que pode provocar mudanças de comportamento, como um momento de reflexão, onde policiais, professores, instrutores e movimentos sociais possam falar de igual para igual, sem os ranços do autoritarismo e do militarismo. Nesse processo de reflexão, procura-se mostrar que existe um inimigo da sociedade a ser combatido, que o militarismo e a ideologia militar não contribuem para entender os conflitos decorrentes das redes de sociabilidade e poder, que a segurança pública deve estar a serviço do cidadão e que as práticas de controle social e repressão à criminalidade não são incompatíveis com os direitos humanos e o Estado de Direito. Entender que a solução para o problema da criminalidade e da violência policial está além das leis e dos códigos criminais. Nesse sentido, as ciências humanas (sociologia, psicologia, antropologia, direitos humanos, filosofia) podem ser parceiras no diagnóstico e na busca de compreensão do aumento da violência e da criminalidade na sociedade atual. Neste início de século XXI, vivemos um "novo tempo" que nos desafia a pensar soluções e práticas inovadoras, capazes de dar respostas aos novos problemas e às novas questões sociais colocadas para a sociedade e para o governo. Essas questões exigem reflexões e soluções coletivas. Foi-se o tempo da solução tomada de forma isolada, sem planejamento, sem a participação da sociedade, vinda de "cima para baixo". O tempo democrático, baseado na democracia e regulado pelo Estado de Direito, exige de todos os atores sociais responsabilidades e parcerias na busca de soluções para a questão da violação dos direitos humanos e o fortalecimento da cidadania.

O debate acerca do controle da violência policial é mais do que justo e necessário, porém, não se pode continuar criticando e punindo policiais sem que se corrijam as distorções na sua formação e se ofereçam oportunidades para se capacitarem. O modelo de controle social em vigor durante os regimes autoritários, em que o uso indiscriminado da força que resultava em violência policial era tolerado e por vezes estimulado por governantes, requer reformas urgentes na formação, planejamento e gestão de recursos humanos. Precisamos entender que a cultura da 
violência é uma construção social, surge e desenvolve-se em contextos sociais onde as redes de solidariedade estão em crise ou passando por mudanças profundas. A violência desenvolve-se também dentro de organizações que não respeitam as regras e as normas aproveitando-se da falta de controle dos serviços oferecidos à população. A ideologia do militarismo, ainda presente nas corporações policiais, precisa ser, de vez, (des)construída e desvalorizada como orientadora das práticas dos profissionais da segurança do cidadão. Essa ideologia não condiz com o perfil dos profissionais de segurança e não contribui para o fortalecimento da cidadania civil numa sociedade marcada pelo Estado de Direito.

Para finalizar, reproduziria uma tese de O'Donnel e Paulo Sérgio Pinheiro (1997:47) segundo o qual: “em países de democracias recentes a transição para o Estado de Direito se dá em dois momentos: o primeiro de resgate da ordem jurídica legítima e segundo momento é aquele em que colocamos em prática as conquistas da nova ordem democrática". Mato Grosso encontra-se ainda nessa primeira fase de transição. Conquistamos a democracia, mas ainda não conseguimos construir modelos de procedimentos e práticas de controle social que não firam a ordem democrática, isto é, que respeitem a cidadania e as leis em vigor. Esse continua sendo o grande desafio das nossas instituições policiais, assim como das universidades e de seus centros de pesquisa na busca da construção de um modelo de polícia cidadã no Brasil e em Mato Grosso.

Mas, desde a transição democrática e a instalação do Estado Democrático de Direito no Brasil, foi somente a partir da segunda metade dos anos 90 que, de fato, a sociedade e os governantes começaram a se preocupar com a questão da violência policial e com a necessidade de reformulação nos currículos voltados para os profissionais de segurança pública. Passaram a pensar em uma polícia que não fosse apenas defensora dos direitos humanos, mas também resguardadora e promotora dos direitos humanos (Balestrelli, 1998). É preciso, portanto, que as universidades repensem o seu papel no ensino policial à luz dos novos paradigmas voltados para o fortalecimento da cidadania. Só assim poderemos cobrar mais das nossas polícias em relação aos comportamentos antiprofissionais. De fato, não dá mais para tolerar um modelo de polícia baseado no uso da força de forma indiscriminada, injustificada, como se admitia antes da conquista do Estado de Direito.

Por isso, é importante insistir que a formulação de um novo modelo de polícia deve começar, necessariamente, por um projeto político pedagógico que contemple novos referenciais teóricos metodológicos adequados ao novo momento que estamos vivendo na área da segurança pública. Estas são questões sociais e teóricas que dizem respeito diretamente ao papel e à responsabilidade das universidades. A UFMT caminha a passos firmes nos últimos anos na construção de um modelo de polícia cidadã, sintonizada com as novas questões sociais que emergiram em nossa realidade, que deve respeitar e, ao mesmo tempo, promover os direitos humanos e da cidadania. Investir em novas metodologias, visando uma melhor profissionalização, o gerenciamento de crises e de controle social mais a eficiência na prevenção ao crime e nas investigações criminais, é uma prioridade inadiável. Punir policiais como forma de dar exemplo e não deixar que os maus exemplos contagiem toda a instituição é necessário. Porém, é preciso ir além do "vigiar e punir" (Foucault, 1987). É preciso pensar na formação e na profissionalização dos quadros de segurança pública. As novas políticas não podem continuar focadas apenas na repressão ao crime e nos excessos de poder praticados no ofício de polícia. Portanto, para controlar efetivamente a violência policial é preciso valorizar o policial, investir em novas metodologias e instrumentos de controle social, profissionalizar os policiais para que minimizem o uso da força física e implementar políticas de segurança voltadas para a prevenção, gerenciamento de crises, solução e/ou administração de conflitos sociais com o emprego mínimo da violência ilegítima ou legítima. Para finalizar, pode-se dizer: culturas boas, eticamente defensáveis devem ser preservadas; já aquelas baseadas na violência, no desrespeito às diferenças de toda natureza, às leis e ao Estado de Direito devem ser suprimidas das nossas relações sociais. Parece, assim, que nem à polícia, nem à sociedade interessa uma polícia despreparada para lidar com os novos conflitos sociais e com a criminalidade crescente. A universidade, nesse sentido, tem uma dívida com a sociedade que começa a ser regatada com sua contribuição para a construção de uma Polícia Democrática e Cidadã. Esse é o nosso desafio, urgente e inadiável.

\section{NOTAS}

1. “Cuiabá é mais violenta que Nova York. A maior cidade norte-americana teve o ano passado 10 mortes por 100 mil habitantes, em Cuiabá este índice foi de 45 mortes por 100 mil. Com pelo menos 290 assassinatos registrados o ano passado (1998), Cuiabá é quatro vezes e meia mais violenta que a região de Nova York que, no mesmo período teve 730 homicídios(...), o que representa 10 mortes por 100 mil habitantes.(...) Cuiabá e Várzea Grande, possui uma taxa de 45 mortes por 100 mil habitantes onde moram cerca de 630.000 pessoas. No Brasil, a Grande Cuiabá perde somente para as cidades de São Paulo e Rio de 
Janeiro, em número de mortes violentas. A média brasileira é de 25. (...) Polícia culpa os traficantes pelo aumento dos índices". Diário de Cuiabá. Cuiabá, 18/04/1999.

2. Desde a sua criação, em 1994, a Corregedoria Militar abriu 671 IPMs, 971 sindicâncias e 243 PADMs para apurar a conduta de integrantes da corporação. Ao todo, 127 foram excluídos, sendo quatro oficiais. Dados da Corregedoria de Polícia Militar de Mato Grosso. 2001.

3. "Tragédia Nacional: Cuiabá é a quarta cidade mais violenta do Brasil”, diz Unesco. A Gazeta. Cuiabá, 15/08/2000. Noticiário Geral. "Vergonha: Cuiabá é a capital campeã em assassinatos contra jovens". A Gazeta. Cuiabá, 17/08/2000. Noticiário Geral.

4. Significa a adequação entre o comportamento da polícia e os objetivos da comunidade.

5. "Vingança - Comerciante defende a pistolagem. Comerciantes que já foram vítimas de bandidos não escondem que, se for preciso, até pagam para matar um bandido.(...) Não tem essa não. Se assaltarem mais uma vez minha casa ou meu comércio e se a polícia não prender os bandidos, eu vou pagar para matá-los. Hoje, minha casa vive cercada de segurança”. A Gazeta. Cuiabá, 02/07/2000.

"Policial admite que 'bater em preso é normal'. A tortura de presos é rotina em delegacias de Mato Grosso, contrariando a Constituição Federal, que garante integridade física e psicológica aos detentos. A constatação é baseada na resposta de um policial civil da capital, que não quis se identificar. Ele falou da tortura policial com a naturalidade de quem comenta a missa". A Gazeta. Cuiabá, 29/08/2000.

"Policial afirma que as pessoas mortas por ela não fazem falta(...) Muito pelo contrário, as pessoas até aplaudem quando um bandido tomba Nunca sequer pensei no que fiz. Sempre dormi tranqüilo ao lado de minha esposa e de meus filhos(...). O oficial da PM diz(...) que os bandidos estão agindo a vontade, porque não existe um modelo definido de segurança. (...) O pior é que quem está matando agora são os justiceiros. $\mathrm{O}$ Cabeção, por exemplo, é um deles. Ele já matou muita gente, inclusive pessoas inocentes. Isso é perigoso, pois até para matar é preciso ter arte", afirma oficial da Polícia Militar que assume que já matou 11 pessoas. $\mathrm{O}$ mesmo oficial declara que, se as polícias Civil e Militar estivessem "trabalhando como antigamente" não apenas os índices de roubos e latrocínios teriam diminuídos, mas também os casos de homicídios não estariam tão elevados. A Gazeta. Cuiabá, 09/07/2000. Polícia.

"Vítima morreu implorando clemência. Em agosto de 1997, o soldado José Moretti do Espírito Santo, o 'Rambo', matou a tiros de metralhadora os únicos dois filhos de Cacilda Rosa Ferreira, além de atirar no pé do marido dela, Manoel Ferreira.(...) Depois de receber sua cerveja, ele reclamou que a bebida estava quente. Disse que, caso não recebesse uma bebida gelada, iria resolver o problema do seu jeito". A Gazeta. Cuiabá, 17/11/2000.

6. A violência em Cuiabá, segundos os dados divulgados por Viana (2000), apresenta três características básicas: está em curva ascendente (é bem maior em 1999 do que em anos anteriores); esta cada vez mais qualificada, ao contrário de muitas capitais brasileiras em que vêm crescendo mais os crimes contra o patrimônio; em Cuiabá os crimes que mais crescem são os crimes contra a vida. Ressalta-se ainda o fato dessa violência estar concentrada em bairros onde vivem as populações pobres e segregadas (em 15\% dos bairros concentram-se 50\% das ocorrências registradas)

7. Os indicadores utilizados por Viana (2000) revelaram em 1999 um grau de violência semelhante ao de São Paulo, cidade 20 vezes maior do que Cuiabá. O índice de violência para 1999 é estimado em 831 ocorrências por $100 \mathrm{mil} /$ habitantes, contra 975 por $100 \mathrm{mil} /$ habitantes de São Paulo. Já o índice de violência contra o patrimônio foi de 3.094 por 100 mil em Cuiabá, contra 3.813 mil por 100 mil para São Paulo.

8. O convênio foi assinado em 10/07/93 entre a PMMT, representada pelo comandante Cel. PM Dival Pinto Martins Correa, e a reitora da Universidade Federal de Mato Grosso, Prof ${ }^{a}$ Luzia Guimarães.

\section{REFERÊNCIAS BIBLIOGRÁFICAS}

A GAZETA. Cuiabá, 2000.

ADORNO, S.; CARDIA, N. Dilemas do Controle Democrático da Violência: execuções sumárias e grupos de extermínio. In: TAVARES DOS SANTOS, J.V. (Org.). Violência em Tempo de Globalização. São Paulo: Hucitec, 1999.

ALBUQUERQUE, C.F.L. Escola de Bravos: cotidiano e currículo numa Academia de Polícia Militar. Dissertação (Mestrado em Sociologia) - Universidade Federal da Bahia. Faculdade de Filosofia e Ciências Humanas. Salvador, 1999.

BALESTRELLI, R.B. Direitos Humanos: coisa de polícia. Passo Fundo, CPEC/Anistia Internacional, 1998.

BRETAS, M.L. Observações sobre a falência dos modelos policiais. Tempo Social, São Paulo, Editora USP, n.9, maio 1997.

CALDEIRA, T.P. do R. Cidade de Muros. São Paulo, Edusp, 2000.

CANO, I. Letalidade da Ação Policial no Rio de Janeiro. Rio de Janeiro: Iser, 1997.

CHAVIGNY, P. Definindo o papel da polícia na América Latina. In: PINHEIRO, P.S. et al. (Orgs.). Democracia, violência e injustiça. O não Estado de Direito na América Latina. Rio de Janeiro: Paz e Terra, 2000.

Police Violence in the Americas. New York Press, 1995.

DIÁRIO DE CUIABÁ. Cuiabá, 1999.

ELIAS, N. O processo civilizador. J. Zahar, 1999.

FOUCAULT, M. Vigiar e Punir. Petrópolis-RJ: 1987.

MESQUITA NETO, P. Violência policial no Brasil: abordagens teóricas e práticas de controle. In: PANDOLFR, D.C. et al. (Orgs.) Cidadania, justiça e violência. Rio de Janeiro: Ed. FGV, 1999.

O’DONNELL, G. A democracia no Brasil. Dilemas e perspectivas. São Paulo: Vértice, 1988.

PINHEIRO, P.S. Violência, crime e sistemas policiais em países de nova democracia. Revista da USP, v.9, n.1, maio 1997.

SKOLNICK, J.H. Justice without trial. Law enforcement in democratic society. New York: MacMillan, 1966.

TAVARES DOS SANTOS, J.V. Os Matuchos. Exclusão e Luta. Do Sul para Amazônia. Petrópolis-RJ: Vozes, 1997a.

A arma e a flor. Formação da organização policial, consenso e violência. Revista da USP, São Paulo, v.9, n.1, maio $1997 \mathrm{~b}$.

Cidadania dilacerada. Revista Crítica de Ciências Sociais, Coimbra, n.37, jun. 1993.

UNESCO BRASIL. A violência contra os jovens no Brasil II. 2000. Disponível em: <http://www.unesco.org.br>.

VIANA, G. O Mapa da violência. Assembléia Legislativa de Mato Grosso. Cuiabá, 2000. Disponível em:

<http://www.gilney.com.br>. (Deputado do PT).

WEBER, M. Os três tipos puros de dominação legítima. In: COHN, G. (Org.). Max Weber. São Paulo: Ática, 1991.

WIEVIORKA, M. O novo paradigma da violência. Revista da USP, São Paulo, v.9, n.1, maio 1997.

Naldson Ramos da Costa: Professor do Departamento de Sociologia e Política da UFMT, faz parte do Grupo de Pesquisa "Violência e Cidadania" na UFRGS. Membro-fundador do Núcleo Interinstitucional de Estudos da Violência e Cidadania na UFMT. 